\title{
DESENVOLVIMENTO DE GENÓTIPOS DE MAMOEIRO TOLERANTES À MANCHA FISIOLÓGICA ${ }^{1}$
}

\author{
FERNANDA DE OLIVEIRA PINTO², HELAINE CHRISTINE CANCELA RAMOS ${ }^{2}$, \\ DEISY LÚCIA CARDOSO ${ }^{2}$, LUCAS NUNES DA LUZ², MESSIAS GONZAGA PEREIRA ${ }^{3}$
}

RESUMO - O mamoeiro é uma das fruteiras tropicais de grande impacto na fruticultura brasileira. Os principais entraves à expansão da cultura são a baixa variabilidade genética e a ocorrência de doenças que encarecem a produção. Neste contexto, realizou-se um cruzamento entre os genótipos 'JS12' e 'Golden' na expectativa de se transferir a característica coloração verde-clara da casca dos frutos (característica Golden), associada à tolerância da mancha fisiológica do mamoeiro, do genitor 'Golden' para o genitor 'JS12'. A variação genética entre e dentro das progênies segregantes obtidas foi avaliada na população $\mathrm{RC}_{1} \mathrm{~S}_{1}$. Três indivíduos possuidores da característica Golden $\left(38 \mathrm{RC}_{1} \mathrm{~S}_{1}-11,30 \mathrm{RC}_{1} \mathrm{~S}_{1}-10\right.$ e $\left.31 \mathrm{RC}_{1} \mathrm{~S}_{1}-10\right)$ foram selecionados pela análise de agrupamento. Estas progênies aliam maior proporção genômica do genitor recorrente (JS12) e bons atributos morfoagronômicos, sendo os mais indicados para o avanço das autofecundações e retrocruzamentos em mamoeiro.

Termos para indexação: Carica papaya L., estresse abiótico, análise multivariada, retrocruzamento.

\section{DEVELOPMENT OF PAPAYA GENOTYPES (Carica papaya $\mathbf{L}$.) TOLERANT TO SKIN FRECKLES}

\begin{abstract}
Papaya is a tropical fruit of high impact in Brazilian fruit crop. The main barriers to the expansion of the crop are reduced genetic variability and disease occurrence that results in the more expensive production. In this context it was made a cross between the genotypes 'JS12' and 'Golden' in the expectation of transferring the trait pale green peel of the fruit (Golden trait), associated as tolerant papaya skin freckles from the 'Golden' genitor to the 'JS12' genitor. The population $\mathrm{BC}_{1} \mathrm{~S}_{1}$ was evaluated for its genetic variation between and within segregating progenies. Three individuals possessing the Golden characteristics $\left(38 \mathrm{BC}_{1} \mathrm{~S}_{1}\right.$ $11,31 \mathrm{BC}_{1} \mathrm{~S}_{1}-10$ and $30 \mathrm{BC}_{1} \mathrm{~S}_{1}-10-10$ ) were selected. These progenies combine greater genomic proportion of the recurrent parent and good morphoagronomic attributes being the most suitable for the advancement of self pollination and backcrossing in papaya.
\end{abstract}

Index terms: Carica papaya L., abiotic stress, multivariate analysis, backcross.

${ }^{1}$ (Trabalho 075-13). Recebido 28-02- 2013. Aceito para publicação em: 12-11-2013.

${ }^{2}$ Drs. em Genética e Melhoramento de plantas, Universidade Estadual do Norte Fluminense Darcy Ribeiro, Campos dos GoytacazesRJ. E-mail: nandapinto@hotmail.com, helaine@uenf.br, deisycardoso@hotmail.com, lucasluzbreeder@gmail.com

${ }^{3}$ Phd in Plant Breeding, Prof. Titular da Universidade Estadual do Norte Fluminense Darcy Ribeiro, Campos dos Goytacazes- RJ. E-mail: messias@uenf.br 


\section{INTRODUÇÃO}

O mamoeiro é uma das principais fruteiras cultivadas no mundo. É amplamente difundido pelas regiões tropicais e subtropicais, sendo também de grande relevância para o agronegócio brasileiro que, nos últimos anos, tornou-se um dos líderes na produção de mamão (FAO, 2011), alcançando em 2011 uma produção de 1,9 milhão de toneladas, $17 \%$ da produção mundial (AGRIANUAL, 2011). No Brasil, as áreas de cultivo têm-se expandido constantemente em decorrência da demanda internacional e do mercado interno. Os principais entraves ao crescimento contínuo da cultura do mamão são o reduzido número de cultivares disponíveis, a severidade de doenças e alguns distúrbios abióticos que encarecem ou inviabilizam a produção.

Entre os distúrbios abióticos, a mancha fisiológica do mamoeiro-MFM, é a mais impactante na produção e tem sido constantemente associada a grandes perdas na comercialização. No fruto, a mancha causa alterações na casca que conferem um padrão de manchas irregulares com maior intensidade na face do fruto exposta à radiação solar direta, depreciando seu valor comercial. A MFM é o resultado do extravasamento de conteúdo dos laticíferos no tecido subepicárpico em função de alterações bruscas na pressão interna desses condutores de látex, normalmente causada por variações ambientais (CAMPOSTRINI et al., 2005; REIS et al., 2008; OLIVEIRA; VITÓTIA, 2011).

Os mecanismos de controle da mancha fisiológica ainda não estão completamente elucidados, apesar de ter sido relatada em plantios comerciais desde a década de 60 . Sabe-se, porém, que o aumento na pressão interna nos laticíferos, que ocasiona a MFM, está associada a vários fatores ambientais, como o excesso de água no solo, baixas temperaturas ou amplitudes térmicas diárias muito altas, aliadas a alta umidade do ar (ELOISA et al., 1994), porém não há um entendimento exato de como estas variáveis se relacionam, sozinhas ou em conjunto, influenciando ou não na ocorrência do distúrbio.

Apenas os fatores do ambiente, atuando sobre o tecido vegetal, podem não ser capazes de desencadear os sintomas da MFM. Existe também maior ou menor predisposição do tecido em função da densidade desses vasos no fruto e da estrutura da parede dos laticíferos. O que se sabe é que há, provavelmente, uma diferença em nível de tecido em determinados genótipos que confere maior tolerância em alguns genótipos, como sugerem Oliveira et al. (2005). Assim, a obtenção de material genético tolerante faz parte das estratégias de ação a curto e médio prazos para minimizar os prejuízos decorrentes da ocorrência desse distúrbio. Uma alternativa seria o desenvolvimento de genótipos com frutos de coloração da casca verde-clara tida como tolerantes a este distúrbio, como o genótipo Golden, que possui casca dos frutos verde-clara. (CAMPOSTRINI et al., 2005; GOMES FILHO et al., 2006; GOMES FILHO et al., 2007).

Nos últimos anos, a expectativa sobre a cultivar 'Golden', tida como tolerante à MFM, tem diminuído, porém esta cultivar ainda se comporta como tolerante à MFM quando comparada às demais variedades do grupo solo. No momento, enquanto se aprofunda a compreensão dos mecanismos da MFM, obtenção de linhagens com coloração de frutos verdeclara, como na variedade 'Golden', é de interesse imediato dos produtores e também para os programas de melhoramento, pois o aspecto qualitativo do fruto é também um fator preponderante na escolha deste como produto pelo mercado.

A característica Golden para coloração da casca do fruto, a julgar por cruzamentos anteriores realizados entre a referida cultivar e outras de casca de fruto verde-escura, tem demonstrado herança recessiva. Nestes casos, transferência de genes para uma característica específica pode ser feita via retrocruzamentos. No mamoeiro, o uso de retrocruzamentos é relativamente simples e pode ser usado em casos desta natureza para incorporação de características pontuais em genótipos-elite, inclusive com possibilidades de se acompanhar os retrocruzamentos com marcadores de DNA, diminuindo os ciclos de seleção com amplas possibilidades de monitoramento da variabilidade genética durante os ciclos de seleção, como sugerem Ramos et al. (2011).

Em mamoeiro, cultura que normalmente apresenta baixa variabilidade (KIM et al., 2002) e com pouquíssimas cultivares disponíveis no mercado, a busca por novas linhagens promissoras para originarem cultivares ou serem pais de híbridos, é de extrema importância para o progresso da cultura. Neste aspecto, o monitoramento da variabilidade genética entre as progênies durante a seleção contribui sobremaneira com a preservação da variabilidade, crucial para a obtenção de progênies segregantes com alta viabilidade para a seleção e deve estar presente nos programas de melhoramento, contribuindo com o conhecimento do perfil das novas linhas em desenvolvimento (MÁRIC et al., 2004; REIF et al., 2005; BERTAN et al., 2009).

Neste trabalho, procurou-se transferir os genes responsáveis pela característica Golden, 
monitorados via cor verde-clara da casca dos frutos, para um dos genótipos parental do híbrido "UENF/ Caliman 01". Para tanto, foi desenvolvido um programa de retrocruzamento, tendo como parental doador a cultivar 'Sunrise Golden' e, recorrente, o genitor "JS12" do referido híbrido. Adicionalmente, foi avaliada a distância genética entre e dentro das progênies segregantes para a característica Golden, utilizando dados morfoagronômicos com o intuito de auxiliar na seleção de genótipos superiores para o avanço das gerações de autofecundação e retrocruzamento.

\section{MATERIAL E MÉTODOS}

\section{Material genético}

As progênies segregantes da autofecundação da primeira geração de retrocruzamento $\mathrm{RC}_{1} \mathrm{~S}_{1}$ avaliadas foram derivadas do cruzamento inicial entre o genótipo do grupo Formosa JS12 (genitor recorrente) e o genótipo do grupo Solo, cv. Golden (genitor doador). Esse cruzamento teve como finalidade transferir para o genótipo JS12 um dos parentais do híbrido "UENF/Caliman 01", a característica Golden, que se tem mostrado associada à tolerância à mancha fisiológica do mamoeiro. Ao que tudo indica, o gene responsável por essa característica é recessivo. Essa característica manifesta-se nas plantas através de uma coloração verde-clara nas folhas, planta e casca do fruto.

Foram avaliadas primeiramente cento e vinte e seis plantas (três testemunhas) pertencentes a sete progênies segregantes para característica 'Golden' (Tabela 1). Nestes materiais, foi realizada uma seleção branda, sendo selecionadas as progênies com a característica 'Golden' com melhor perfil produtivo. Posteriormente, foram avaliados somente vinte e quatro indivíduos oriundos da pré-seleção, possuidores da característica Golden acrescentados de dois indivíduos 'Golden' não selecionados previamente $\left(31 \mathrm{RC}_{1} \mathrm{~S}_{1}\right.$ e $\left.37 \mathrm{RC}_{1} \mathrm{~S}_{1}\right)$. Ambas as análises contaram com três testemunhas (JS12-genitor recorrente, 'Golden' (genitor doador) e o 'Sunrise Solo 72/12'). Os genótipos foram avaliados com base em características morfoagronômicas (variáveis quantitativas, qualitativas e binárias).

\section{Local e delineamento experimental}

$\mathrm{O}$ experimento foi instalado em junho de 2009, contudo os dados foram coletados ao longo de dois anos agrícolas de 2009/2010 e 2010/2011, na área comercial da empresa Caliman Agrícola S/A (Fazenda Romana), localizada no município de Linhares, no Estado do Espírito Santo. Foi utilizado o delineamento em blocos ao acaso, com 19 tratamentos (16 $\mathrm{RC}_{1} \mathrm{~S}_{1}$ e 3 testemunhas), quatro repetições e 10 plantas por parcela, com espaçamento de 3,50 m entre fileira e de $1,50 \mathrm{~m}$ entre plantas na fileira. As adubações, o manejo, o controle de pragas e doenças, e os tratos culturais utilizados seguiram os mesmos adotados nos plantios comerciais da empresa.

\section{Características morfoagronômicas ava- liadas}

Os dados de campo foram coletados entre 150 e 270 dias após o plantio no campo, a depender da característica como se segue: diâmetro do caule aos 150 dias (DC), altura da planta aos 150 e 270 dias $\left(\mathrm{ALTP}_{1}\right.$ e $\left.\mathrm{ALTP}_{2}\right)$, altura da inserção do primeiro fruto aos 150 dias (AIPF), número de frutos totais aos 150;180 e 270 dias ( $\mathrm{NFT}_{1}, \mathrm{NFT}_{2}$ e NFT $)$, número de frutos carpeloides aos 150 e 270 dias $\left(\mathrm{NFC}_{1}\right.$ e $\mathrm{NFC}_{2}$ ), número de frutos pentândricos aos 150 e 270 dias ( $\mathrm{NFP}_{1}$ e $\left.\mathrm{NFP}_{2}\right)$, número de nós sem fruto aos 180 e 270 dias $\left(\mathrm{NNSF}_{1}\right.$ e $\left.\mathrm{NNSF}_{2}\right)$, número de frutos comerciais por planta aos 180 e 270 dias (NFCom e $\mathrm{NFCom}_{2}$ ), produção total de frutos aos 180 e 270 dias ( $\mathrm{PROD}_{1}$ e $\mathrm{PROD}_{2}$ ), peso médio de frutos (PMF), comprimento do fruto (COMF), diâmetro do fruto (DIAMF), firmeza da polpa (FI), firmeza externa do fruto (FE), teor de sólidos solúveis ( $\left.{ }^{\circ} \mathrm{BRIX}\right)$, espessura média da polpa do fruto (ESP), diâmetro da cavidade interna (DCAV), produtividade total por planta (PRODT), índice de ocorrência da pinta-preta (Pi), índice de ocorrência da Mancha Fisiológica do Mamoeiro (MFM), Formato da cavidade central do fruto (FCavF), Coloração da casca do fruto (CCasF), esta, sendo tomada pela presença da característica Golden (nota 0) e ausência desta (nota 1)

\section{Análise dos dados}

Inicialmente, todas as características morfoagronômicas foram submetidas à análise de variância (ANOVA) no programa estatístico SAS - Statistical Analyses Sistem Release (SAS, 2002), com exceção da característica cor da casca do fruto (CorCasc) a fim de se verificar a existência de variabilidade. A fonte de variação 'genótipo' foi considerada como de efeito aleatório.

A análise de dissimilaridade genética foi realizada considerando os mesmos dados morfoagronômicos para todos os cento e vinte e seis indivíduos, inicialmente, e em seguida somente para os vinte e quatro indivíduos pré-selecionados que apresentaram a característica Golden. A matriz de distância genética foi obtida com base no algoritmo de Gower (1971) que suporta análise de dados 
quantitativos, qualitativos e binários em uma única análise obtida pelo programa R (R Development Core Team, 2006).

Os genótipos foram agrupados pelo método hierárquico UPGMA (Unweighted Pair-Group Method Using an Arithmetic Average), com o auxílio do programa MEGA versão 5 (TAMURA et al., 2011), o ajuste entre a matriz de distância e a matriz de agrupamento foi estimado pelo coeficiente de correlação cofenética (CCC), obtido pelo programa R. A significância das correlações entre matrizes foi estimada pelo teste de Mantel, com 1.000 permutações. Para análise das Coordenadas Principais (PCA), foi utilizado o programa Genalex 6.3. (PEAKALL; SMOUSE, 2006)

\section{RESULTADOS E DISCUSSÃO}

Para a seleção entre as progênies segregantes, a característica cor dos frutos (Figura 1) foi primordial para a identificação dos genótipos a serem selecionados, dentro destas, as de melhor desempenho agronômico. Entre as progênies segregantes, foram selecionadas as progênies $30 \mathrm{RC}_{1} \mathrm{~S}_{1}, 31 \mathrm{RC}_{1} \mathrm{~S}_{1}$, $32 \mathrm{RC}_{1} \mathrm{~S}_{1}, 33 \mathrm{RC}_{1} \mathrm{~S}_{1}, 34 \mathrm{RC}_{1} \mathrm{~S}_{1}, 36 \mathrm{RC}_{1} \mathrm{~S}_{1}, 37 \mathrm{RC}_{1} \mathrm{~S}_{1}$ e $38 \mathrm{RC}_{1} \mathrm{~S}_{1}$ que apresentaram a característica Golden, sendo estas candidatas ao avanço de gerações de retrocruzamento e autofecundação.

Detectou-se variabilidade fenotípica entre as progênies avaliadas com base nas características morfoagronômicas (Tabela 2). Para a característica altura da inserção do primeiro fruto (AIPF), quase todas as progênies segregantes apresentaram valores abaixo dos encontrados para a testemunha 'Golden' $(100,2 \mathrm{~cm})$.

Uma ampla variabilidade entre as progênies avaliadas foi encontrada para a característica número de frutos totais para as três épocas avaliadas, aos $150 ; 180$ e 270 dias após o transplantio ( $\mathrm{NFT}_{1}, \mathrm{NFT}_{2}$ e NFT 3 ). A progênie $32 \mathrm{RC}_{1} \mathrm{~S}_{1}$ foi a que apresentou valores mais baixos para o número de frutos totais para as três épocas avaliadas, porém a maioria das progênies apresentou média acima de 20 frutos. Por outro lado, quando se considerou o número de frutos deformados (carpeloides-NFC e pentândricos-NFP), nota-se maior variação na ocorrência da carpeloidia. Resultados similares foram encontrados por Silva et al. (2008).

A produtividade das progênies $\left(\mathrm{PROD}_{1}\right.$, $\mathrm{PROD}_{2}, \mathrm{PRODT}$ ) apresentou alta variação entre 1,1 a 33,9 (kg/planta), porém tanto para as progênies como para os indivíduos dentro das progênies Golden a média foi significativamente superior à média da testemunha Golden $(12,8 \mathrm{~kg} /$ planta $)$, uma das cultivares mais plantadas nas regiões produtoras de mamão do País.

Para as características relacionadas à qualidade do fruto, a primeira característica avaliada, peso do fruto (PF), permitiu observar uma variação entre 494,6 g e 709,8 g entre as progênies segregantes. Esse resultado já era esperado, haja vista que as progênies avaliadas são provenientes de um cruzamento inicial entre um genitor Formosa (JS12) e outro genitor Solo (Golden). Peso de fruto, além de contribuir para a produtividade, é de importância na determinação deste como produto e deve ser explorado nos dois sentidos (fruto grande e pequeno), a depender do nicho de mercado a ser explorado, contudo espera-se um aumento na média do peso de frutos à medida que os genótipos incorporem o genoma do parental recorrente JS12 (SILVA et al., 2008; IDE et al., 2009).

As características comprimento do fruto (COMPF) e diâmetro do fruto (DIAMF) variaram nas progênies segregantes, em média ,de 105,0 a $116,7 \mathrm{~mm}$ para COMPF e $64,1 \mathrm{a} 88,5 \mathrm{~mm}$ para DIAMF. Quanto à firmeza do fruto (FE) e à firmeza da polpa (FI), estes variaram entre 105,0 e 114,4 $\mathrm{mm}$ para FE e 82,1 a $89,9 \mathrm{~mm}$ para FI, valores considerados moderados, porém superiores às testemunhas, indicando razoável progresso genético. Em conjunto com a firmeza, o teor de sólidos solúveis totais ( ${ }^{\circ} \mathrm{BRIX)}$ é de grande importância, pois são parâmetros da qualidade do fruto. $\mathrm{O}^{\circ} \mathrm{BRIX}$ apresentou valores entre 9,9 e 11,0 com destaque para progênie $33 \mathrm{RC}_{1} \mathrm{~S}_{1}$ que mostrou maior valor para tal característica. Os valores para ${ }^{\circ} \mathrm{BRIX}$ foram aferidos em frutos no estádio entre 0 e 1 . Assim, espera-se um aumento considerável nestes quando aferidos em estádios de maturação mais elevados, próximos ao ponto de consumo dos frutos.

As progênies também foram avaliadas quanto à incidência de mancha fisiológica do mamoeiro (MFM) e da doença fúngica pinta-preta (Pi). Com relação à $\mathrm{Pi}$, em média, não houve variação entre e dentro das progênies avaliadas. Já em relação à incidência da MFM, houve moderada variação entre e dentro das progênies, sendo encontrados valores de ocorrência entre muito baixa $(0)$ e baixa ocorrência (1), de acordo com a escala proposta por Gomes Filho et al. (2006). Deste modo, a população segregante para a característica Golden (frutos verde-claro) mostra comportamento semelhante ao genótipo doador 'Golden', indicando que a população sob retrocruzamento apresenta viabilidade para exploração da tolerância a MFM nos linhas subsequentes do programa de retrocruzamentos.

As avaliações realizadas para incidência 
da MFM foram feitas em épocas distintas, por ocasiões das colheitas de fruto, procurando englobar as principais épocas de ocorrência da MFM. Entre as épocas, o mês de setembro é considerado o de maior ocorrência da MFM, segundo Campostrini et al. (2005) e Gomes Filho et al. (2007). O fenômeno da sazonalidade da MFM descrito por estes mesmos autores também deve ser levado em consideração, pois a temperatura e a amplitude térmica são as características de maior importância quando da ocorrência da MFM.

$\mathrm{Na}$ Tabela 3, encontram-se os respectivos quadrados médios para as características morfoagronômicas avaliadas. Com exceção de ESPP e $\mathrm{Pi}$, todas as demais características apresentaram variabilidade significativa pelo teste $\mathrm{F}$, demonstrando o potencial da população para seleção.

$\mathrm{O}$ coeficiente de variação genotípica $(\mathrm{CVg})$ permite uma avaliação da variabilidade genotípica para as diferentes características, e auxilia na definição das estratégias de melhoramento. Para a maioria das características o $\mathrm{CVg}$ mostrou valores moderados a altos, $30 \%$ em média, com exceção de $\mathrm{NFCOM}_{2}$, que foi nulo (Tabela 2). Os maiores valores encontrados para $\mathrm{CVg}$ foram para as características PROD $_{1}$ e MFM, 93,99 e 121, respectivamente, sugerindo possibilidade de ganhos expressivos no processo de seleção para produtividade e tolerância a MFM.

O coeficiente de variação experimental (CVe), indicativo da precisão experimental, variou entre baixo e moderado, $20 \%$ em média, indicando boa precisão, apesar de algumas características, como NFC, NFP, $\mathrm{PROD}_{1}, \mathrm{NFC}_{2}, \mathrm{NFP}_{2}, \mathrm{Pi}$, MFM e ESPP, apresentarem altos valores. Estes resultados atestam a forte influência ambiental de que estas características são objeto. Resultados similares, CVe alto, são descritos por Silva et al. (2008) para algumas características que envolvem contagem de frutos (comerciais, carpeloides e pentândricos).

Uma maneira de se utilizarem os coeficientes de variação genético e ambiental de forma mais acurada é considerá-los conjuntamente através do índice de variação (Iv). Quando o Iv é maior que a unidade, este indica considerável variabilidade genética para a característica. Pela Tabela 2, as características AIPF, ALTP, $\mathrm{NFT}_{1}, \mathrm{NFT}_{2}, \mathrm{NFC}$, $\mathrm{NFCOM}, \mathrm{ALT}_{2}, \mathrm{NFT}_{3}, \mathrm{NFC}_{2}, \mathrm{NNSF}_{2}, \mathrm{PF}, \mathrm{COMPF}$, DIAMF, FI e PROD apresentaram valores superiores à unidade, demonstrando amplo potencial para a seleção (FALEIRO et al., 2004). Estes são em função dos coeficientes de variação genotípico e fenotípico. Alguns trabalhos em mamão relacionam Iv superiores à unidade para muitas características das listadas aqui (IDE et al., 2009; DIAS et al., 2011; RAMOS et al., 2011), contudo houve uma variação considerada no $\mathrm{I}_{\mathrm{V}}$ indo de $0\left(\mathrm{NFCOM}_{2}\right)$ a 2,27 (COMPF). Quando nulo, o (Iv) demonstra baixo potencial de resposta à seleção.

Outro parâmetro de grande importância é a estimativa de herdabilidade. Na Tabela 2, com exceção de $\mathrm{NFCOM}_{2}$ MFM, ESSP e DCAV, todos os valores de herdabilidade $\left(\mathrm{h}^{2}\right)$ foram superiores a $60 \%$, indicando elevado potencial de resposta à seleção. Valores ainda maiores para $\mathrm{h}^{2}$ foram observados para AIFP (88,50\%), ALTP (87,87\%), NFT $(87,15 \%)$, $\mathrm{NFT}_{2}(90,62 \%), \operatorname{NFC}(83,43 \%), \operatorname{NFCOM}(89,11 \%)$, $\operatorname{ALTP}_{2}(89,82 \%), \mathrm{NFT}_{3}(94,45 \%), \mathrm{NFC}_{2}(89,79 \%)$, $\mathrm{NNSF}_{2}(89,28 \%), \mathrm{PF}(93,76 \%), \mathrm{COMPF}(95,40 \%)$, DIAMF $(82,99 \%)$ e PRODT $(80,04 \%)$.

No mamoeiro, apesar de ser uma espécie sensível às flutuações ambientais, valores de herdabilidade acima de $70 \%$ são possíveis em diversas características (SILVA et al., 2008). Entre todas as características, os valores descritos para $\mathrm{NFT}_{1}, \mathrm{NFT}_{2}$ e NFT 3 são de grande importância, pois resultam em maior produção total. Valores altos de herdabilidade para número de frutos em mamoeiro também foram descritos por Ide et al. (2009).

\section{Divergência entre e dentro das progênies segregantes para Golden}

A análise da divergência genética foi, primeiramente, realizada para todos os cento e vinte e seis (3 testemunhas) indivíduos pertencentes às progênies segregantes $\left(\mathrm{RC}_{1} \mathrm{~S}_{1}\right)$, com base nos dados quantitativos, qualitativos e binários, utilizando a distância de Gower através do programa MEGA. $\mathrm{Na}$ Figura 2, observa-se o agrupamento dos genótipos pelo método UPGMA. Os indivíduos com a característica Golden foram marcados no dendrograma, para facilitar visualização. Os indivíduos da progênie $31 \mathrm{RC}_{1} \mathrm{~S}_{1}$ não estão presentes nesta avaliação devido a terem sido excluídos na pré-seleção realizada anteriormente.

O ajustamento das matrizes de dissimilaridade e de agrupamento foi avaliado através do coeficiente de correlação cofenética (CCC) com 0,72 , o que indica um razoável ajuste entre as matrizes. Quando os valores da correlação cofenética se aproximam da unidade, estas são tomadas como ideais, pois representam maior acurácia na formação do dendrograma. Valores médios de coeficiente de correlação cofenética em mamão podem ser obtidos (SILVA et al., 2007; RAMOS et al., 2011; RAMOS et al., 2012). Apesar do valor moderado para CCC, o ajustamento das matrizes pode ser considerado satisfatório, uma vez que a correlação entre matrizes 
foi significativa pelo teste de Mantel, a $5 \%$ de probabilidade.

Definindo como ponto de corte a região onde ocorreu a mudança mais abrupta no dendrograma, foram formados sete grupos. O primeiro grupo (I) foi constituído por indivíduos das progênies $30 \mathrm{RC}_{1} \mathrm{~S}_{1}$, $32 \mathrm{RC}_{1} \mathrm{~S}_{1}, 33 \mathrm{RC}_{1} \mathrm{~S}_{1}, 37 \mathrm{RC}_{1} \mathrm{~S}_{1}, 38 \mathrm{RC}_{1} \mathrm{~S}_{1}$ além do genitor recorrente JS12 e portadores da característica Golden pré-selecionados $\left(30 \mathrm{RC}_{1} \mathrm{~S}_{1}-538 \mathrm{RC}_{1} \mathrm{~S}_{1}\right.$ $12,34 R C_{1} S_{1}-16,38 R C_{1} S_{1}-7$ e $\left.34 R_{1} C_{1} S_{1}-21\right)$. Estes representam genótipos potencias para o avanço de geração, pois possuem a característica de interesse (Golden) aliada aos demais atributos fenotípicos e proximidade ao genitor recorrente (JS12).

Os grupos II e IV foram constituídos apenas por indivíduos normais, ou seja, que não possuíam a característica Golden (CorCasca $=1)$. Deste grupo, nenhum indivíduo foi selecionado. $\mathrm{O}$ grupo III alocou um indivíduo Golden $\left(33 R_{1} \mathrm{~S}_{1}-1\right)$.

$\mathrm{O}$ grupo $\mathrm{V}$ foi constituído pelos indivíduos Golden, 38RC $\mathrm{S}_{1}-11,30 \mathrm{RC}_{1} \mathrm{~S}_{1}-10,30 \mathrm{RC}_{1} \mathrm{~S}_{1}-16 \mathrm{e}$ por indivíduos das progênies $30 \mathrm{RC}_{1} \mathrm{~S}_{1}, 32 \mathrm{RC}_{1} \mathrm{~S}_{1} \mathrm{e}$ $37 \mathrm{RC}_{1} \mathrm{~S}_{1}$. O grupo VI alocou o maior número de indivíduos com a característica Golden, além do genitor doador "Golden", indicando possivelmente uma maior proximidade entre estes e o doador Golden. Os indivíduos Golden pertencentes a este grupo foram o $33 \mathrm{RC}_{1} \mathrm{~S}_{1}-14,33 R \mathrm{C}_{1} \mathrm{~S}_{1}-19,30 R \mathrm{R}_{1} \mathrm{~S}_{1}-1$, $37 \mathrm{RC}_{1} \mathrm{~S}_{1}-14,37 \mathrm{RC}_{1} \mathrm{~S}_{1}-10,38 \mathrm{RC}_{1} \mathrm{~S}_{1}-9,34 \mathrm{RC}_{1} \mathrm{~S}_{1}-4$, $34 \mathrm{RC}_{1} \mathrm{~S}_{1}-2$ e $34 \mathrm{RC}_{1} \mathrm{~S}_{1}-3$.

O último grupo (VII) foi formado por indivíduos Golden, 30RC $\mathrm{S}_{1}-6,33 \mathrm{RC}_{1} \mathrm{~S}_{1}-18 \mathrm{e}$ $33 \mathrm{RC}_{1} \mathrm{~S}_{1}-8$, porém mais distantes do genitor recorrente e próximos à testemunha do grupo Solo SS72/12. Neste caso, estes genótipos podem ser interpretados como próximos ao genitor doador, uma vez que a cultivar Golden é mutação do SS72/12 e ambos são bastante similares do ponto de vista genético.

A análise da divergência genética, através do programa MEGA, foi também realizada somente para os indivíduos com a característica Golden e as três testemunhas (Figura 3 ). O coeficiente de correlação cofenética (CCC) para o agrupamento foi 0,84 , indicando boa aproximação entre as matrizes gráfica e de distância. De acordo com essa análise foram formados sete grandes grupos, sendo que o primeiro grupo reuniu o genitor doador (Golden) e os indivíduos $33 \mathrm{RC}_{1} \mathrm{~S}_{1}-14$ e $33 \mathrm{RC}_{1} \mathrm{~S}_{1}-19$. Tais genótipos foram os mais próximos do genitor doador, de acordo com as características morfoagronômicas avaliadas, como peso e comprimento do fruto, ou seja, possuindo pesos e tamanhos menores, bem parecidos com o genótipo Golden.
$\mathrm{O}$ grupo II reuniu o maior número de indivíduos, a saber: $37 \mathrm{RC}_{1} \mathrm{~S}_{1}-14 ; 37 \mathrm{RC}_{1} \mathrm{~S}_{1}-10$; $30 \mathrm{RC}_{1} \mathrm{~S}_{1}-1 ; 38 \mathrm{RC}_{1} \mathrm{~S}_{1}-9 ; 37 \mathrm{RC}_{1} \mathrm{~S}_{1}-7 ; 38 \mathrm{RC}_{1} \mathrm{~S}_{1}-7$; $34 \mathrm{RC}_{1} \mathrm{~S}_{1}-16 ; 34 \mathrm{RC}_{1} \mathrm{~S}_{1}-21 ; 30 \mathrm{RC}_{1} \mathrm{~S}_{1}-5 ; 38 \mathrm{RC}_{1} \mathrm{~S}_{1}-12$; $31 \mathrm{RC}_{1} \mathrm{~S}_{1}-21 ; 33 \mathrm{RC}_{1} \mathrm{~S}_{1}-8$.

O grupo III alocou o genitor recorrente (JS12) e os indivíduos $31 \mathrm{RC}_{1} \mathrm{~S}_{1}-10 ; 30 \mathrm{RC}_{1} \mathrm{~S}_{1}-10 ; 38 \mathrm{RC}_{1} \mathrm{~S}_{1}$ $11 ; 33 \mathrm{RC}_{1} \mathrm{~S}_{1}-1 ; 30 \mathrm{RC}_{1} \mathrm{~S}_{1}-16$. Tais indivíduos são promissores ao avanço de geração, pois, além de possuírem a característica Golden, são os mais próximos e, provavelmente, com maior proporção genômica do genitor recorrente o JS12. O grupo IV alocou somente um genótipo (testemunha SS72/12), e o grupo $\mathrm{V}$ reuniu três indivíduos da mesma progênie segregante, o $34 R_{1} \mathrm{~S}_{1}-3 ; 34 \mathrm{RC}_{1} \mathrm{~S}_{1}-2$ e $34 \mathrm{RC}_{1} \mathrm{~S}_{1}-4$. Os grupos VI e VII alocaram somente um indivíduo cada, sendo estes os indivíduos $33 \mathrm{RC}_{1} \mathrm{~S}_{1}-18 \mathrm{e}$ $30 \mathrm{RC}_{1} \mathrm{~S}_{1}-6$, respectivamente.

Os indivíduos com a característica Golden, além de analisados através da divergência genética, também foram analisados a partir da dispersão gráfica baseada na análise da coordenada principal (PCA), conforme apresentada na Figura 4. As duas primeiras coordenadas juntas explicaram $57,3 \%$ da variação total dos dados, sendo que $33,8 \%$ dessa variação foi explicada pela coordenada 1 e $23,5 \%$ explicada pela coordenada 2.

Tais valores, apesar de serem considerados moderados, indicam uma confiabilidade da dispersão apresentada, contudo deve-se ressaltar que não houve uma nítida separação entre indivíduos de progênies mais similares e dissimilares. Na dispersão, pelas diferentes cores no gráfico, nota-se que os genótipos de diferentes progênies formam um único grupo mais próximos à testemunha 2 (SS72/12) .

Os indivíduos mais similares ao genitor recorrente, testemunha 1 (JS12), foram as progênies $38 \mathrm{RC}_{1} \mathrm{~S}_{1}, 30 \mathrm{RC}_{1} \mathrm{~S}_{1}$ e $31 \mathrm{RC}_{1} \mathrm{~S}_{1}$ resultado similar ao obtido pelo método UPGMA. Do outro lado, os indivíduos da progênie $33 \mathrm{RC}_{1} \mathrm{~S}_{1}$ foram mais similares ao genitor doador testemunha 3 (Golden), corroborando também o agrupamento obtido pelo UPGMA.

As demais progênies foram mais similares à testemunha $2(\mathrm{SS72/72})$. Estes, pertencentes à progênie $33 \mathrm{RC}_{1} \mathrm{~S}_{1}$ ficaram bem próximos ao genitor doador, enquanto o indivíduo $26\left(38 \mathrm{RC}_{1} \mathrm{~S}_{1}-11\right)$ foi o mais próximo ao genitor recorrente, resultado similar ao encontrado pela análise da diversidade, seguido dos indivíduos 10 (31RC $\left.\mathrm{R}_{1}-21\right), 13\left(33 \mathrm{RC}_{1} \mathrm{~S}_{1}-14\right)$, $7\left(30 \mathrm{RC}_{1} \mathrm{~S}_{1}-10\right), 8\left(30 \mathrm{RC}_{1} \mathrm{~S}_{1}-16\right), 9\left(31 \mathrm{RC}_{1} \mathrm{~S}_{1}-10\right)$, $24\left(38 \mathrm{RC}_{1} \mathrm{~S}_{1}-7\right)$ e $17\left(34 \mathrm{RC}_{1} \mathrm{~S}_{1}-3\right)$ mostraram-se mais próximos ao genitor recorrente (JS12).

Pelo exposto nas três análises, três indivíduos 
possuidores da característica Golden $\left(38 \mathrm{RC}_{1} \mathrm{~S}_{1}-11\right.$, $30 \mathrm{RC}_{1} \mathrm{~S}_{1}-10$ e $31 \mathrm{RC}_{1} \mathrm{~S}_{1}-10$ ) apresentaram-se como os genótipos mais promissores ao avanço de geração de autofecundação e retrocruzamento devido à presença do caráter coloração da casca do fruto, maior proporção genômica do genitor recorrente e boa média para as principais características de seleção.

Alternativamente, além da continuação dos retrocruzamentos para a recuperação do recorrente (JS12), pode-se inferir que os demais indivíduos possuidores da característica Golden também podem vir a contribuir com a continuação do programa, em outra via. Parte das linhagens Golden aqui obtidas possuem perfil para se tonarem linhagens que poderiam ser incorporadas ao banco de germoplasma da UENF/Caliman com vista à utilização futura. Este cruzamento no sentido contrário pode ser trabalhado também como um enriquecimento da cultivar Golden, cultivar mais plantada no País, ainda assim com qualidade de polpa e firmeza, entre outros, inferior a outros genótipos do grupo Solo.

A cultivar Golden vem apresentando nos últimos anos, incidência crescente de MFM, podendo estar associado ao fato de que esta cultivar, uma linhagem, vem sendo propagada indistintamente em várias partes do País, onde com muita frequência se encontram produtores que produzem sua própria semente. O processo de seleção, no sentido apenas da produção de frutos, pode ter sido fundamental na seleção de plantas menos tolerantes às doenças. Contudo, as avaliações que se seguem nos campos experimentais da Caliman Agrícola, a cultivar Golden ainda supera as demais no quesito tolerância a MFM.

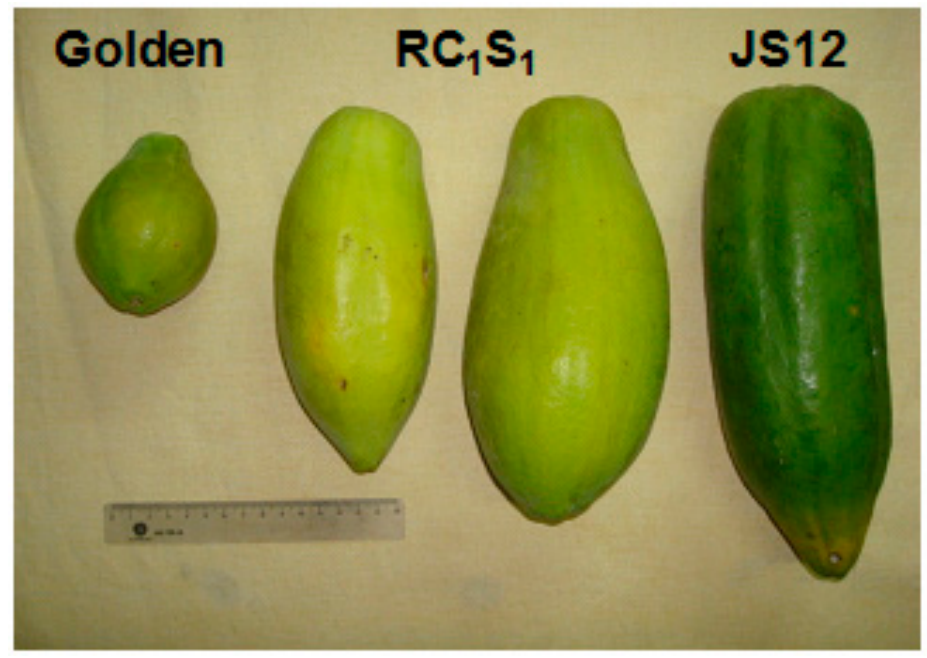

FIGURA 1 - Identificação da característica ‘Golden' (frutos verde claros) em frutos de indivíduos avaliados neste estudo. Campos dos Goytacazes, UENF, 2011. 


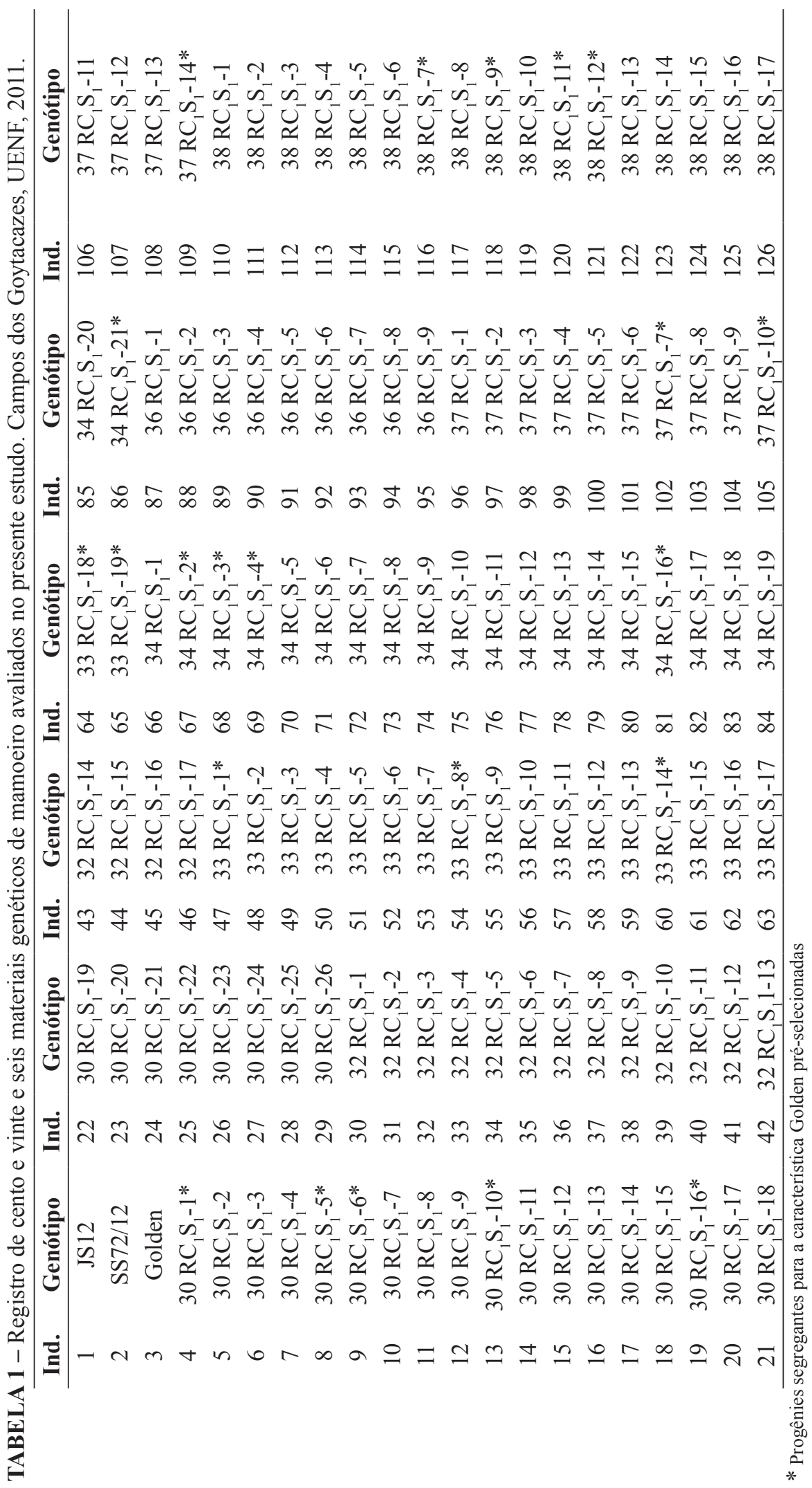



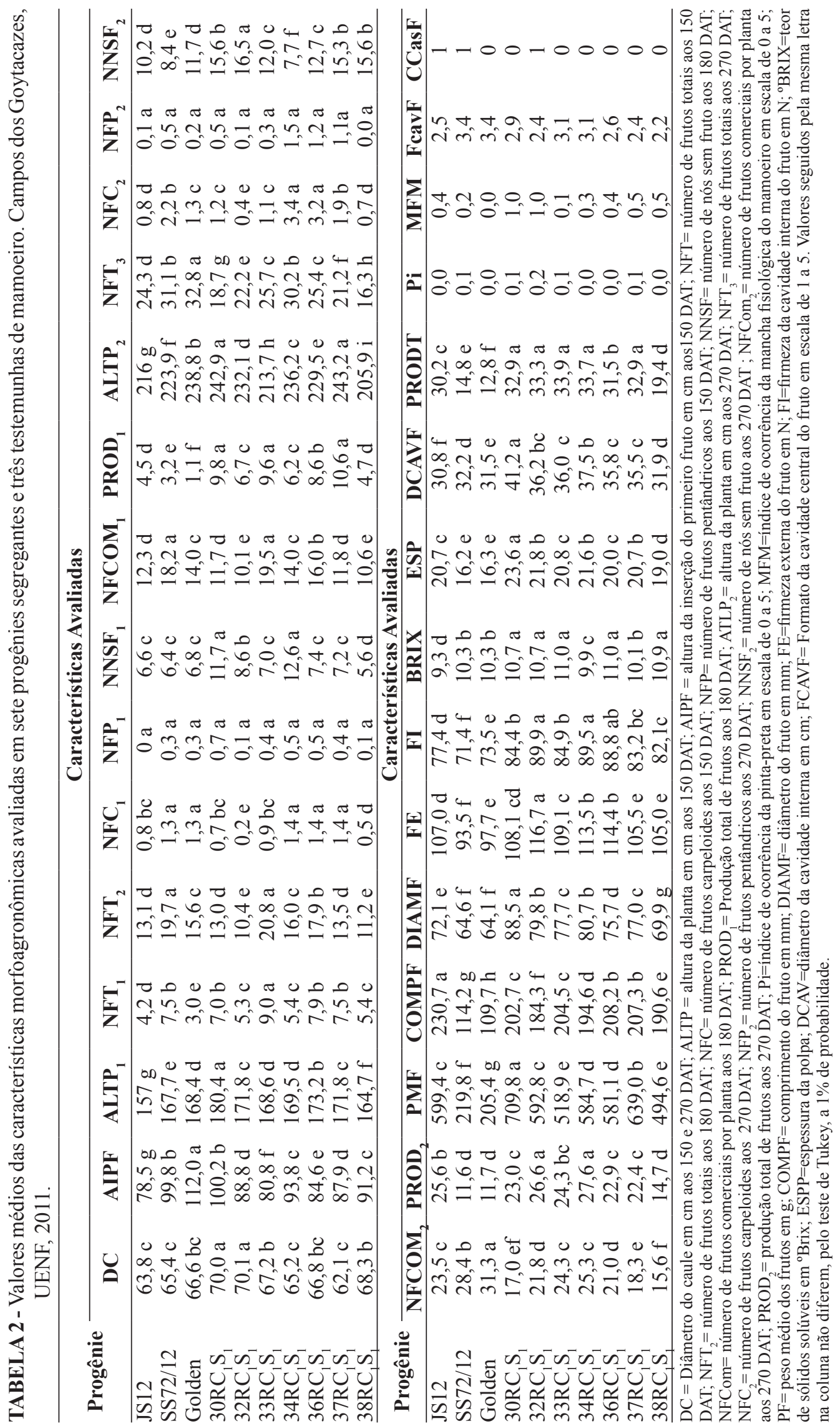


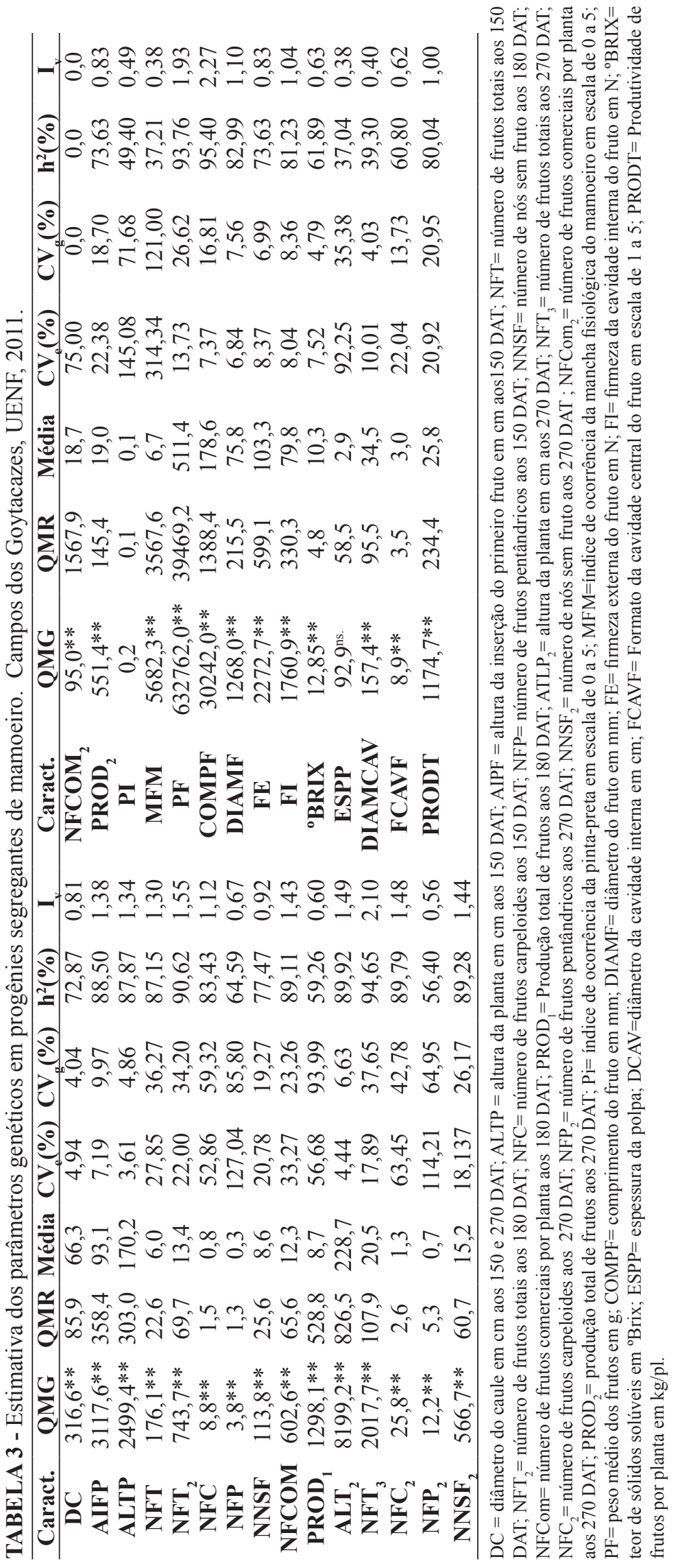




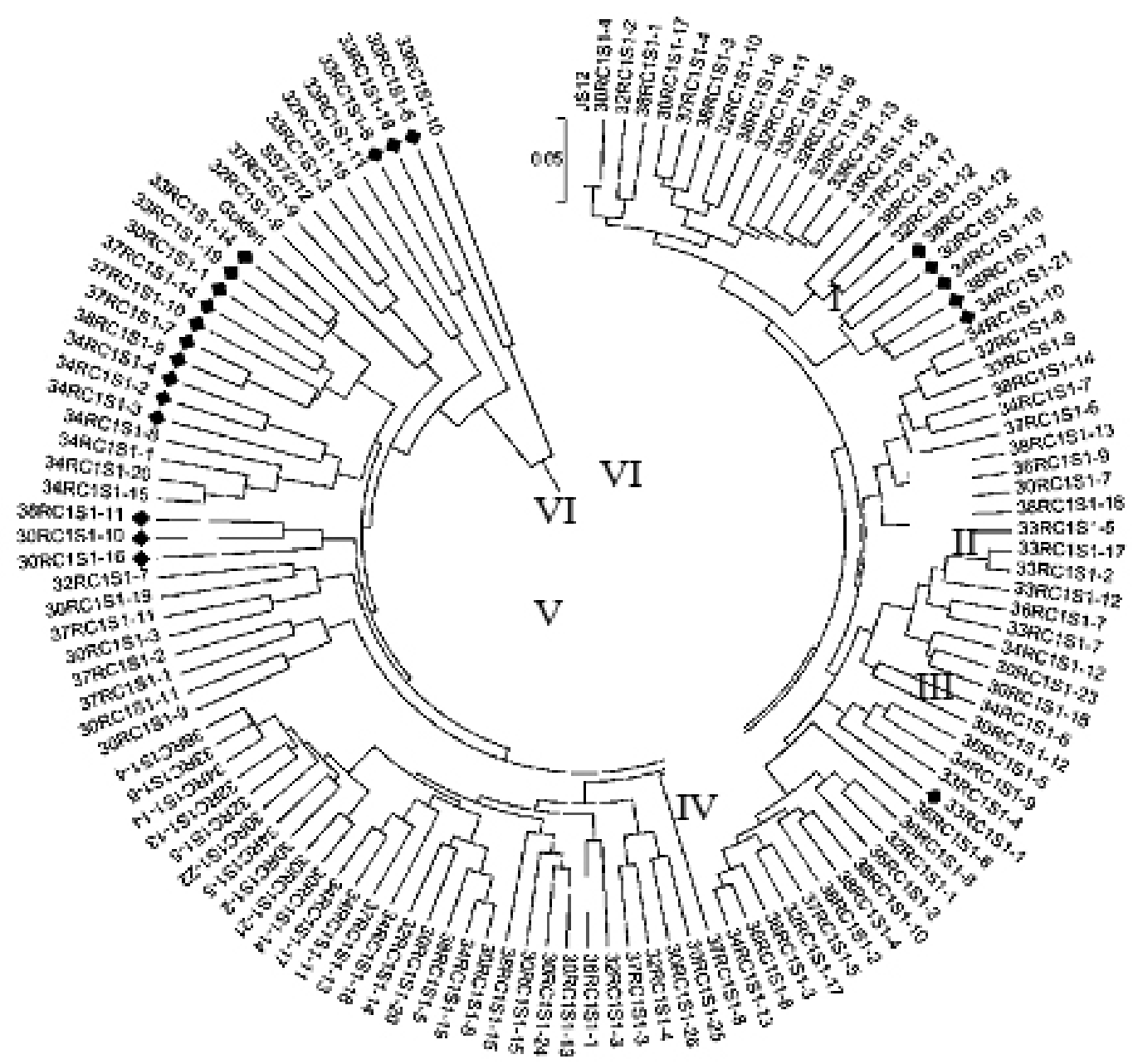

FIGURA 2 - Agrupamento UPGMA para 126 indivíduos $\left(\mathrm{RC}_{1} \mathrm{~S}_{1}\right)$ de mamoeiro e 3 testemunhas (CCC 0,72). - Indivíduos Golden. Campos dos Goytacazes, UENF, 2011. 


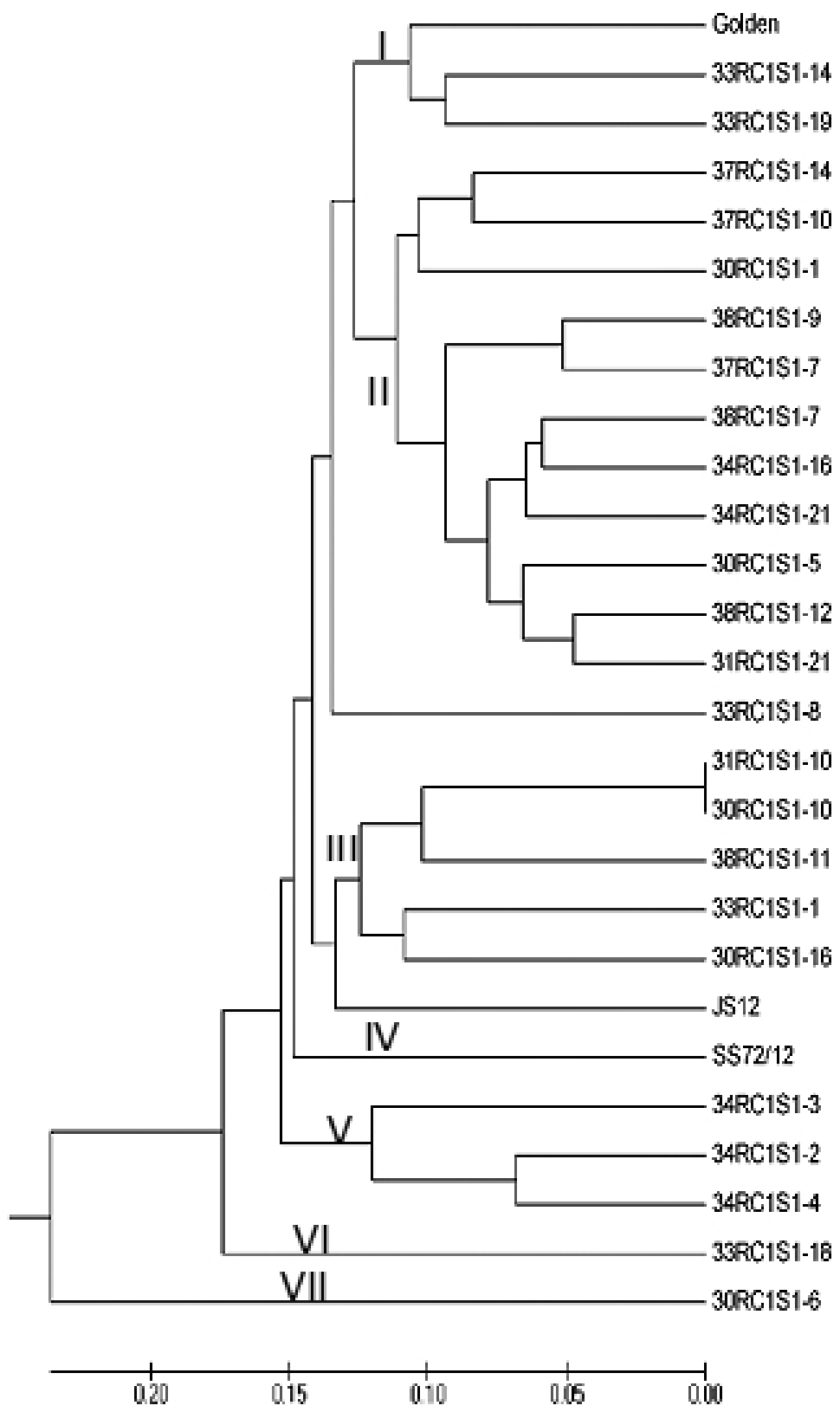

FIGURA 3 - Agrupamento UPGMA baseado na análise dos indivíduos $\left(\mathrm{RC}_{1} \mathrm{~S}_{1}\right)$ de mamoeiro segregantes para Golden (CCC 0,84). Campos dos Goytacazes, UENF, 2011. 


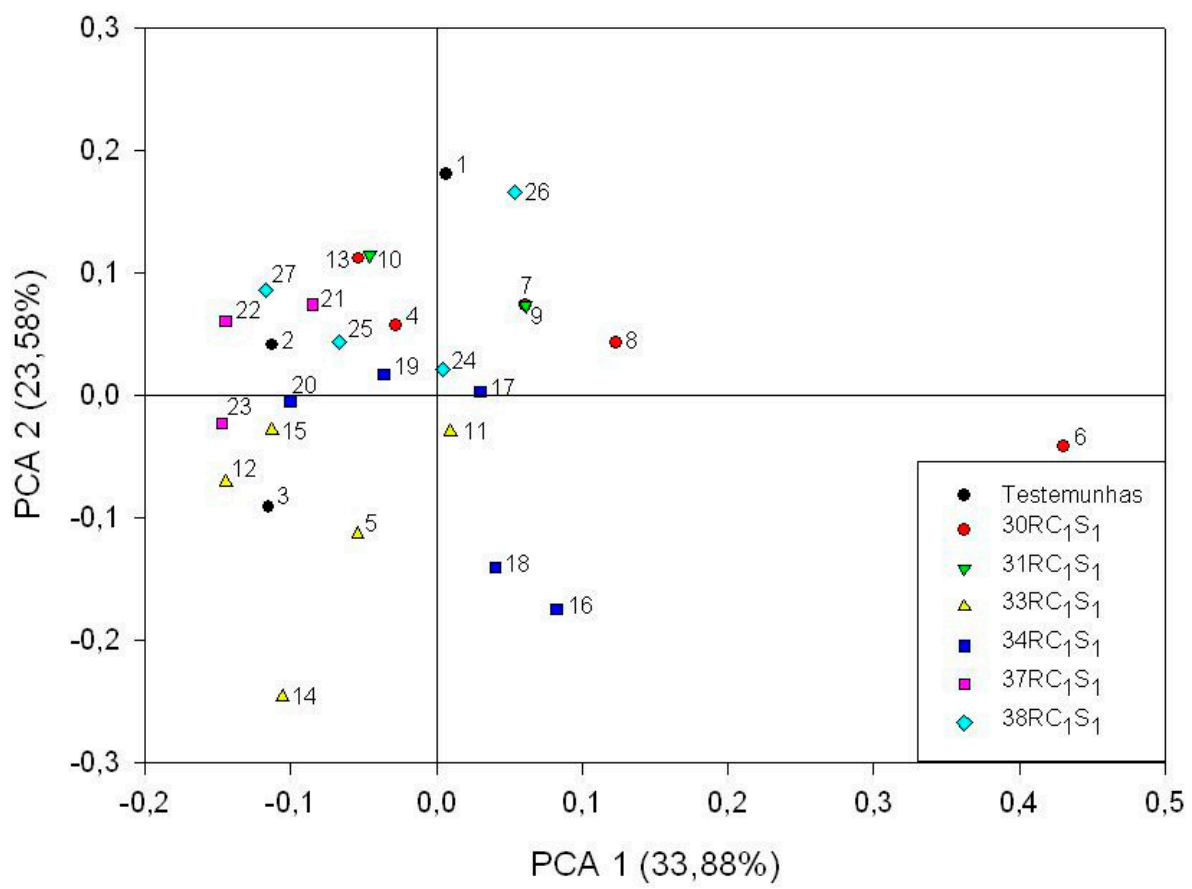

FIGURA 4 - Análise das Coordenadas Principais para 24 indivíduos de mamoeiro segregantes para a característica Golden e três testemunhas (1 - JS12-genitor recorrente; 2 - SS72/12; 3 - Golden). Campos dos Goytacazes, UENF, 2011.

\section{CONCLUSÃO}

1-A transferência do gene responsável pela cor da casca dos frutos é efetiva, permitindo a seleção de progênies segregantes para o caráter e possuidoras de alto valor genético.

2-A incidência da MFM durante as avaliação permite a seleção de linhagens tolerantes, uma vez que estas apresentam notas 0 a 1 na escala de intensidade do distúrbio.

3-A análise da diversidade via algorítimo de Gower é eficaz em agrupar as linhagens próximas a genitor recorrente, facilitando a seleção das que mais se assemelham a este.

\section{AGRADECIMENTOS}

À FAPERJ, pela concessão da bolsa de doutorado à primeira autora; à Empresa Caliman Agrícola S/A, pela condução do experimento; à UENF e ao Curso de Pós-Graduação em Genética e Melhoramento de Plantas da UENF, Campos dos Goytacazes-RJ, pela oportunidade de execução desta pesquisa.

\section{REFERÊNCIAS}

AGRIANUAL. Anuário da Agricultura Brasileira: Mamão. São Paulo: FNP, consultoria e Agroinformativos, 2011, p. 325-332.

BERTAN, I.; CARVALHO, F.I.F.; OLIVEIRA, A.C.; BENIN, G.; VIEIRA, E.A.; VALÉRIO, I.P. Morphological pedigree and molecular distance and their association with hybrid wheat performance. Pesquisa Agropecuária Brasileira, Brasília, v. 44, n. 2, p. $155-163,2009$.

CAMPOSTRINI, E.; LIMA, H.C.; OLIVEIRA, J.G.; MONNERART, P.H.; MARINHO, C.S. Teores de $\mathrm{Ca}$ e variáveis meteorológicas: relações com a mancha fisiológica do mamão no norte fluminense. Bragantia, Campinas, v. 64, p. 601-613, 2005.

DIAS, N.L.P.; OLIVEIRA, E.J.; DANTAS, J.L.L. Avaliação de genótipos de mamoeiro com uso de descritores agronômicos e estimação de parâmetros genéticos. Pesquisa Agropecuária Brasileira, Brasília, v. 46, n. 11, 1.471-1.479, 2011. 
ELOISA, M.; REYES, Q.; PAULL, R.E. Skin freckles on solo papaya fruit. Scientia Horticulturae, Amsterdam, v.58, p.31-39, 1994.

FALEIRO, F.G.; RAGANIN, A.V.; MOREIRA, M.A.; BARROS, E.G. Use of molecular markers to accelerate the breeding of common bean lines resistant o rust and anthracnose. Euphytica, Wageningen, v. 138, n. 3, p. 213-218, 2004.

FAO. Disponível em: www.faostat.org.br. Acesso em: 06 de junho de 2011.

GOMES FILHO, A.; OLIVEIRA, J.G.; VIANA, A.P.; DAMASCENO JÚNIOR, P.C.; PEREIRA, M.G. Lâminas de irrigação e coberturas do solo sobre a incidência da mancha fisiológica e produtividade do mamão "Golden". Ciência Rural, Santa Maria, v. 37, n. 6, p. 1.654-1.660, 2007.

GOMES FILHO, A.; OLIVEIRA, J.G.; VIANA, A.P.; DAMASCENO JÚNIOR, P.C.; PEREIRA, M.G. Validação do método das notas para quantificação da incidência da mancha fisiológica do mamão através do uso de imagens digitais. Revista Brasileira de Fruticultura, Jaboticabal, v. 28, n. 3, p. 365-368, 2006.

GOWER, J.C. General coefficient of similarity and some of its properties. Biometrics, Washington, v. 27, n. 4, p. 857-874, 1971.

IDE, C.D.; PEREIRA, M.G.; VIANA, A.P.; PEREIRA, T.N.S. Use of testers for combining ability and selection of papaya hybrids. Crop Breeding and Applied Biotechnology, Viçosa, MG, v. 9, p. 60-66, 2009.

KIM, M.S.; MOORE, P.H.; ZEE, F.; FITCH, M.M.M.; STEIGER, D.; MANSHARDT, R.; PAULL, R.; DREW, R.A.; SEKIOKA, T.; MING, R. Genetic diversity of Carica papaya as revealed by AFLP markers. Genome, Ottawa, v. 45, n. 3, p. 503-512, 2002.

MÁRIC, S.; BOLARIC, S.; MARTINCIC, J.; PEJIC, I.; KOZUMPLIK, V. Genetic diversity of hexaploid wheat cultivars estimated by RAPD markers, morphological traits and coefficients of parentage. Plant Breeding, Berlin, v. 123, p. 366-369, 2004.
OLIVEIRA, J.G.; PEREIRA, M.G.; MARTELLETO, L.A.P.; IDE, C.D. Mancha fisiológica do mamão: uma perspectiva de obtenção de material genético tolerante. Revista Brasileira de Fruticultura, Jaboticabal, v. 27, n. 3, p. 458- 461, 2005.

OLIVEIRA, J.G.; VITÓRIA, A.P. Papaya: Nutritional and pharmacological characterization, and quality loss due to physiological disorders: An overview. Food Research International, Barking, v. 44, p. 1.306-1.313, 2011.

PEAKALL, R.; SMOUSE P.E. Genalex 6: genetic analysis in Excel. Population genetic software for teaching and research. Molecular Ecology Notes, Oxford, v. 6, p. 288-295, 2006.

RAMOS, H.C.C.; PEREIRA, M.G.; GONÇALVES, L.S.; AMARLA JÚNIRO, A.T.; SCAPIM, C.A. Comparison of multiallelic distances for the quantification of genetic diversity in the papaya. Acta Scientiarum Agronomy, Maringá, v. 33, n. 1, p. 59-66, 2012.

RAMOS, H.C.C.; PEREIRA, M.G.; SILVA, F.F.; GONÇALVES, L.S.A.; PINTO, F.O.; SOUZA FILHO, G.A.; PEREIRA, T.N.S. Genetic characterization of papaya plants(Carica papaya $\mathrm{L}$.) derived from the first backcross generation. Genetics and Molecular Research, Ribeirão Preto, v. 10, n. 1, p. 393-403, 2011.

REIF, J.C.; MELCHINGER, A.E.; FRISCH, M. Genetical and mathematical properties of similarity and dissimilarity coefficients applied in plant breeding and seed bank management. Crop Science, Madison, v. 45, n.1, p. 1-7, 2005.

REIS, L.F.; CAMPOSTIRNI, E.; NETTO, A.T. Skin freckles on Formosa papaya: relationships with soil water potential total soluble solids of latex and climate variables. Ciência e Agrotecnologia, Lavras, v. 32 , n. 5 , p. 1.473-1.480, 2008.

SAS Institute. Statistical analysis system: release 9 (Software). Cary, 2002.

SILVA, F.F.; PEREIRA, M.G.; CAMPOS, W.F.; DAMASCENO JÚNIOR, P.C.; PEREIRA, T.N.S.; SOUZA FILHO, G.A.; RAMOS, H.C.C.; VIANA, A.P.; FERREGUETTI, G.A. DNAmarker-assisted sex conversion in elite papaya genotype (Carica papaya L.). Crop Breeding and Applied Biotechnology, Viçosa, MG, v. 7, p.52-58, 2007. 
SILVA, F.F.; PEREIRA, M.G.; RAMOS, H.C.C.; DAMASCENO JÚNIOR, P.C.; PEREIRA, T.N.S.; GABRIEL A.P.C.; VIANA, A.P. Selection and estimation of the genetic gain in segregating generations of papaya (Carica papaya L.). Crop Breeding and Applied Biotechnology, Viçosa, $\mathrm{MG}$, v. 8 , p. 1-8, 2008 .
TAMURA, K.; PETERSON, D.; PETERSON, N.; STECHER, G.; NEI, M.; KUMAR, S. MEGA5: Molecular Evolutionary Genetics Analysis using Maximum Likelihood, Evolutionary Distance, and Maximum Parsimony Methods. Molecular Biology and Evolution, Chicago, v. 28, p.2731-2739, 2011. 